\title{
USE OF CRUMB RUBBER TO IMPROVE THERMAL EFFICIENCY OF CEMENT-BASED MATERIALS
}

\author{
Ashraf Fadiel, Fouad Al Rifaie, Taher Abu-Lebdeh and Ellie Fini \\ ${ }^{1}$ Department of Civil, Architectural and Environmental Engineering, \\ North Carolina A and T State University, NC 27411, Greensboro, USA
}

Received 2014-01-13; Revised 2014-01-14; Accepted 2014-03-14

\begin{abstract}
Motivated by the tremendous trend toward green environment and to reduce the effect of scrap tires on the environment and human health, this research is an attempt to find a practical and environmentally sound solution of the problem of scrap tires by developing a light weight with low thermal conductivity composite construction materials using waste tires. A few literatures may be found about the effect of crumb rubber on thermal conductivity of mortar. Thus, in this research project, an experimental program was established to investigate the effect of the amount and size of crumb rubber (rubber obtained from recycling scrap tires) on the thermal properties of mortar. Four levels of crumb rubber addition: 10, 20, 30 and 40\% and three sizes of crumb rubber (\#30, \#10_20 and a combination of both sizes) were considered to make twelve different mixtures of the rubberized mortar. Specially designed and constructed heat transfer measurement device was used to measure thermal conductivity of the specimens. Results were used to determine the optimal amount of crumb rubber that gives the least thermal conductivity, which directly related to the improvement in thermal resistance of concrete mixtures. It was found that the size and the amount of crumb rubber had an effect on thermal properties of the specimens investigated. The thermal conductivity of rubberized mortar was decreased by $28 \%$ when crumb rubber \#10_20 was used. It was also found that \#10_20 crumb rubber had more effect on the thermal conductivity reduction than \#30 crumb rubbers. An empirical equation is proposed to predict thermal conductivity of rubberized mortar.
\end{abstract}

Keywords: Crumb Rubber, Cement Mortar, Hot Box, Construction Materials, Thermal Conductivity

\section{INTRODUCTION}

The utilization of recycled and waste materials in construction applications and the solution of environment problem by recycling are becoming greater concern (Bolden et al., 2013). There are many lightweight construction materials that contain recycled fillers such as fly ash (Kearsley and Wainwright, 2001; James et al., 2011), waste glass (Duman et al., 2002), steel slag (Yue et al., 2000; Fiore et al., 2008), lightweight expanded clay aggregates (James et al., 2011; Roshan et al., 2010), foam polystyrene (Laukaitis et al., 2005) and more. Landfills all over the world are filled with tremendous amounts of scrap tires. The disposal of used tires in landfills is becoming unacceptable because of the rapid depletion of available sites for waste disposal. For example, there are two billion scrap tires in the U.S. landfills with over 250 million tires added every year. These stockpiles are dangerous not only due to potential environmental threat, but also from fire hazards and provide breeding grounds for rats, mice and mosquitoes.

Scrap tires present both a challenge and an opportunity. The challenge is in how to dispose them in a safe and sustainable manner, while the opportunity is to turn a waste stream into a resource. The disposal of Corresponding Author: Taher Abu-Lebdeh, Department of Civil, Architectural and Environmental Engineering,

North Carolina A and T State University, NC 27411,

Greensboro, USA Tel: (336) 285-3670, Fax: (336) 334-7126 
waste tires is a serious environmental concern. The chemistry of rubber in these disposed tires plays a major role in the associated environmental pollution. Due to its cross-linked structure, rubber needs a long time for natural degradation. In addition, the presence of stabilizers and additives in rubber further delays the process. Furthermore, the disposal of used tires in landfills, stockpiles, or illegal dumping grounds, increases the risk of accidental fires. There were some incidents where tire fires continued for a few days to several months. Tire fires can be devastating to the environment and neighboring communities. In 1983, a fire took place in a tire storage facility near Winchester, Virginia. This fire continued for almost 9 months. About 7 million tires were burned causing dense black smoke which resulted visibility impairment and covered approximately 50 mile area. The fire causes an environmental damage and air pollutants such as $\mathrm{CO}, \mathrm{NO}_{2}, \mathrm{SO}_{2}$ and oil runoff of 800,000 gallons. Furthermore, a tire can produce about two gallons of oil when it is on fire. Tires are water repellent that leaves fire fighters powerless against large tire fires. In addition, cleanup of tire fire aftermaths is quite expensive and the water used to put out the fires usually becomes a way to carry oil from burning tires. This water mixed with oil can also be a source of contamination to ground water and soil. Tires disposal has become a challenging task and hence innovative solution has to be developed to meet these challenges. Although, very little raw chemical precursor material can be reclaimed for reuse from waste tires, researchers all over the world are constantly trying to find innovative methods to re-use them in different applications such as: Use of tire rubber in asphaltic concrete mixtures; incineration of tires for the production of steam; reuse of ground tire rubber in various plastic and rubber products; fuel for cement kiln, feedstock for making carbon black and as artificial reefs in marine environment. One strategy to utilize used tires is to mechanically reduce them to crumb and subsequently combine the crumb with other materials to form a composite. The idea of use of crumb rubber in asphalt binders was first implemented in 1950's. Since then extensive research has been carried out in this area and currently has become a common practice in the asphalt industry. Fini et al. (2013) investigated the feasibility of the application of scrap tire and swine manure to produce a sustainable alternative for bituminous asphalt used in pavement construction. The biobinder, produced from swine manure, was blended with crumb rubber and asphalt binder (PG 64-22) to produce Biomodified Rubber (BMR) asphalt. Their study compares the rheological properties of BMR with a Crumb Rubber-Modified (CRM) binder commonly being used in the United States. They found that BMR has comparable properties with the CRM binder and that the introduction of the biobinder to the CRM binder was beneficial in improving the low temperature property of the CRM binder while also reducing the CRM binder's overall viscosity. The utilization of crumb rubber is not only beneficial in improving the properties of the asphalt binder but also highly favorable from a sustainability perspective and helps in reducing the carbon footprint. In addition to the use of crumb rubber in asphalt binders, researchers have explored the potential reuse of crumb rubber in cement-based materials (Segre and Joekes, 2000; Sukontasukkul and Wiwatpattanapong, 2009). Extensive studies have been conducted on the use of waste tire modified Portland cement concrete in highway construction. However, previous investigations on the re-use of tire rubber in cement-based materials focus on the use of crumb rubber as an aggregate in concrete and evaluate only its mechanical properties. Two types of rubber aggregates were used: Compact Rubber Aggregates (CRA) and Expanded Rubber Aggregates (ERA). Overall results have indicated that rubberized concrete mixtures posses lower density, increased toughness and ductility, higher impact resistance and better sound insulation. Results have also indicated that rubberized concrete mixtures posses decrease in the mechanical properties such as compressive and splitting tensile strengths and that coarse rubber particle affects the properties more negatively than do fine particles. The reduction in strength may be due to the weak bond between the cement paste and the rubber aggregates causing reduction in overall strength of the matrix. Portland cement concrete with addition of crumb rubber becomes a heterogeneous mixture due to different specific gravities of the ingredients. Previous studies show that although the addition of crumb rubber to Portland cement concrete causes reduction in strength, the loss might be minimized by prior surface treatment of the rubber particles. Studies on the influence of rubber aggregate type on rubberized concrete have demonstrated the importance of rubber particle type with respect to the hydraulic transport properties of the composite (Benazzouk et al., 2004). Benazzouk et al. (2007) have investigated the effect of powdered tire rubber as addition to cement paste on both the physicomechanical and water absorption properties. They concluded that the composite satisfies the basic requirement of construction materials and could be used for load-bearing wall. In addition, the incorporation of rubber particles in cementitious matrix tends to restrict water absorption of the composite. 
Although, extensive work has been done on the mechanical properties of crumb rubber-cement composite, little or no work has been previously reported on the thermal conductivity. This research project is an attempt to develop light weight with low thermal conductivity composite construction materials using waste tires to help solve simultaneously energy and environment concerns by reducing heat transfer into building and recycle used rubber tires. In this study, an experimental test program was conducted mainly to investigate the effect of crumb rubber particles addition on the thermal conductivity of cement paste composite. The surface of the crumb rubber was modified to increase its adhesion to cement paste. A sodium hydroxide $(\mathrm{NaOH})$ solution was used as surface treatments.

\section{EXPERIMENTAL PROGRAM}

An experimental program was developed to investigate the effect of crumb rubber addition on the thermal properties of some construction materials. Cement mortar mixtures were mixed with three sizes of crumb rubber, namely, \#10_20, \#30 and mixture of both. A heat transfer measurement device was designed and constructed according to the standards to measure thermal conductivity of the rubberized concrete specimens.

\subsection{Materials}

Crumb rubber: The crumb rubber used in this study was provided by Liberty Tire Recycling Company. The crumb rubber was derived from used tires. Three different sizes of crumb rubber were used, namely, mesh 30 , mesh 10 to 20 and combination of both. Mesh 30 or (\#30) was very fine powder rubber its size (0-0.6) $\mathrm{mm}$ and mesh 10 to 20 (\# 10-20) was coarse rubber its size (0.84-2 mm) (Fig. 1). The specific gravity, density and sieve analysis of the two crumb rubber sizes and the combination of both sizes (\#30 and \# 10_20) were tested and shown in Table 1 and Fig. 2.

The specific gravity and the density were the average of three readings. As shown, crumb rubber \#30 and \# 10_20 had a consistent gradation and it was close to upper and lower limits of the gradation of fine aggregate, while the mixed crumb rubber fill between the limits of the fine aggregate specification.

\subsection{Surface Treatment of Crumb Rubber}

Crumb rubber was surface treated with $10 \%$ concentrated Sodium Hydroxide solution $(\mathrm{NaOH})$. The rubber was first immersed for $20 \mathrm{~min}$ in $\mathrm{NaOH}$ solution. Then the rubber was sieved on sieve No.200, washed with clean water and filtered again and dried at ambient temperature. The $\mathrm{NaOH}$ treatment and water wash helped clean the rubber crumb from any foreign materials that might be attached to the rubber particles.

\subsection{Specimen Preparation}

A total of 13 samples were prepared and tested for unit weight, absorption and thermal conductivity. The water to cement ratio of 0.47 and cement to sand ratio of $1: 3$ were kept constant throughout the experiment (Table 2). The fine aggregate was replaced by different amounts of crumb rubber: $10,20,30$ and $40 \%$ by weight of fine aggregate was replaced by crumb rubber, while other materials were kept constant. Two sizes of crumb rubber (\#30, \#10_20) and combination of both (50\% from each) were used to replace the sand. Specimens were given identification numbers as described in Table 3.

Table 1. Properties of crumb rubber

\begin{tabular}{lrrr}
\hline & Crumb rubber size & \\
& - & \\
Property & $\# 30$ & Mix & $\# 10 \_20$ \\
\hline Specific gravity & 0.51 & 0.59 & 0.78 \\
Density $\left(\mathrm{kg} / \mathrm{m}^{3}\right)$ & 445.00 & 436.00 & 421.00 \\
Fineness modulus & 2.42 & 3.08 & 3.84 \\
\hline
\end{tabular}

Table 2. Mortar mix proportions

\begin{tabular}{lcrrrr}
\hline & Rubber & \multicolumn{3}{c}{ Weight $(\mathrm{Kg})$} \\
Mix ID & \multicolumn{1}{c}{ No.10-20 } & No.30 & Sand & Cement & Water \\
\hline PM & 0.00 & 0.00 & 1350 & 450 & 211.5 \\
10M\#10-20 & 135.00 & 0.00 & 1215 & 450 & 211.5 \\
20M\#10-20 & 270.00 & 0.00 & 1080 & 450 & 211.5 \\
30M\#10-20 & 405.00 & 0.00 & 945 & 450 & 211.5 \\
40M\#10-20 & 540.00 & 0.00 & 810 & 450 & 211.5 \\
10M\#30 & 0.00 & 135.00 & 1215 & 450 & 211.5 \\
20M\#30 & 0.00 & 270.00 & 1080 & 450 & 211.5 \\
30M\#30 & 0.00 & 405.00 & 945 & 450 & 211.5 \\
40M\#30 & 0.00 & 540.00 & 810 & 450 & 211.5 \\
10MMix & 67.50 & 67.50 & 1215 & 450 & 211.5 \\
20MMix & 135.00 & 135.00 & 1080 & 450 & 211.5 \\
30MMix & 202.50 & 202.50 & 945 & 450 & 211.5 \\
40MMix & 270.00 & 270.00 & 810 & 450 & 211.5 \\
\hline
\end{tabular}

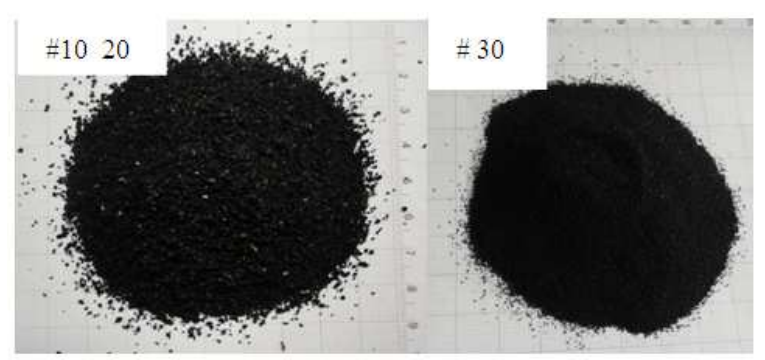

Fig. 1. Crumb rubber \#10_20 and \#30 


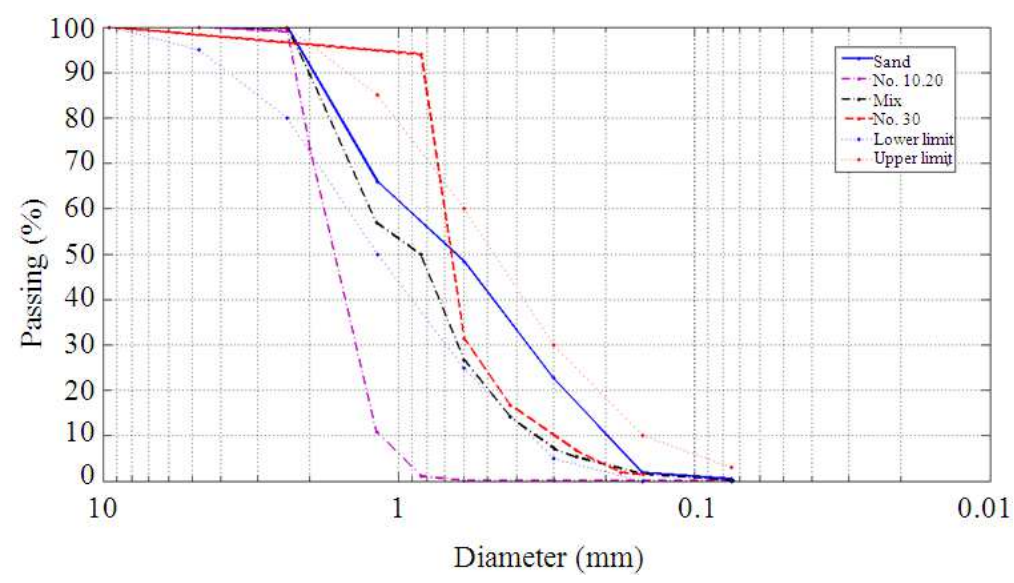

Fig. 2. Gradation of fine aggregate and crumb rubber

Table 3. Mix ID and description of specimens

\begin{tabular}{lll}
\hline No. & Mix ID & Description \\
\hline 1 & PM & Plain Mortar. \\
2 & $10 \mathrm{M} \# 30$ & $10 \%$ of sand replaced with \#30 \\
3 & $20 \mathrm{M} \# 30$ & $20 \%$ of sand replaced with \#30 \\
4 & $30 \mathrm{M} \# 30$ & $30 \%$ of sand replaced with \#30 \\
5 & $40 \mathrm{M} \# 30$ & $40 \%$ of sand replaced with \#30 \\
6 & 10M\#10_20 & $10 \%$ of sand replaced with \#10_20 \\
7 & 20M\#10_20 & 20\% of sand replaced with \#10_20 \\
8 & 30M\#10_20 & 30\% of sand replaced with \#10_20 \\
9 & 40M\#10_20 & 40\% of sand replaced with \#10_20 \\
10 & 10MMix & $10 \%$ of sand replaced with both \\
11 & 20MMix & 20\% of sand replaced with both \\
12 & 30MMix & $30 \%$ of sand replaced with both \\
13 & 40MMix & $40 \%$ of sand replaced with both \\
\hline
\end{tabular}

\subsection{Mixing and Preparing Specimens}

A mixer type Hobart HL 200 was used to mix the materials. Sand, cement and rubber were placed in the mixer at the same time. The materials were dry-mixed for 2-3 min. After a homogenous distribution of the materials, water mixed with super-plactizer was added gradually and mixed for additional $4 \mathrm{~min}$. After confirming that the mix was workable, the mix was poured into the molds. The molds used were specially made for this test. The molds were squares of $304.8 \mathrm{~mm}$ by $304.8 \mathrm{~mm}$ and $25.4 \mathrm{~mm}$ depth (12 in. $\times 12 \mathrm{in.} \times 1 \mathrm{in}$.). After placing mortar into the mold, the mold was vibrated on a vibrating table for $30-60 \mathrm{sec}$. Then excess mortar was removed and the specimen's surface is finished with a steel trowel. The specimens were then covered with plastic for the first $24 \mathrm{~h}$. Afterwards, the specimens were demolded and placed in the cure tank for 28 days. After 28 days, the specimens were removed from the curing tank and dried in an oven for $24 \mathrm{~h}$ at a temperature of $21^{\circ} \mathrm{C}\left(70^{\circ} \mathrm{F}\right)$.

\section{TEST PROCEDURES}

\subsection{Unit Weight and Absorption of Rubberized Cementious Materials}

The unit weight of the fresh rubberized mortar was obtained in accordance with ASTM C642-06. The water absorption of the specimens was tested after 28 days. The specimens were removed from curing tank and then surface dried using a towel. When saturated surface dry condition was achieved, the specimens were weighted and recorded. After that the specimens were oven dried for $24 \mathrm{~h}$ at a temperature of $21^{\circ} \mathrm{C}\left(70^{\circ} \mathrm{F}\right)$ and weighted until constant mass was achieved.

\subsection{Thermal Conductivity Measurement}

A specially designed thermal conductivity measurements device was constructed based on hot box apparatus. The principle of measurement is to place the specimen between two boundaries held at constant temperatures. One side was heated by a heat source and the other side was kept at room temperature. The box was constructed from homogeneous materials that have stable thermal properties and have high thermal resistance and good mechanical properties. The structure of the box shown in Fig. 3 was $113 \mathrm{~cm}$ height, $40.64 \mathrm{~cm}$ width and $40.64 \mathrm{~cm}$ deep $\left(44 \frac{1}{2} \mathrm{in} . \times 16 \mathrm{in} . \times 16\right.$ in.). The thickness of the surrounding chamber was $5.08 \mathrm{~cm}$ (2 in.). In order to minimize heat losses to its surroundings, the chamber was constructed of Extruded Polystyrene (XPS) layer placed between two layers of Maple plywood with a thickness of $0.635 \mathrm{~cm}(1 / 4 \mathrm{in}$.) each. The three layers were assembled using a heavy duty construction adhesive. 


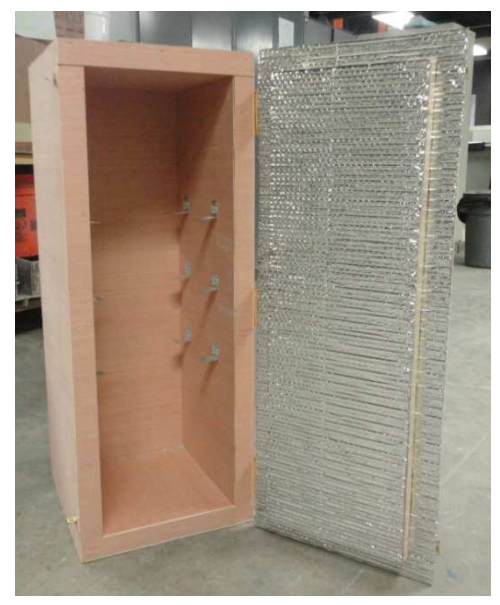

Fig. 3. Adiabatic box photographs

To measure heat flux, the device was equipped with HFP01 heat flux sensors (Fig. 4a). The body of HFP01 was composed of ceramics-plastic and a thermopile embedded in the plastic ceramic composite (thermopile is a set of connected thermocouples that can measure a small quantity of heat flux). To collect the data from HFP01, an accurate voltmeter that has millivolt range was used. HFP01 sensor was calibrated using a guarded hot plate according to ASTM C 177. It has sensitivity (E) of $61.37 \mu \mathrm{V} / \mathrm{W} / \mathrm{m}^{2}$. After the voltage output was collected, the heat flux was calculated based on the following formula:

$\mathrm{Q}=\mathrm{V} / \mathrm{E}$

Where:

$\mathrm{Q}=$ Heat flux $\mathrm{W} / \mathrm{m}^{2}$,

$\mathrm{V}=$ Measured voltage and

$\mathrm{E}=$ Sensor sensitivity $\left(61.37 \mu \mathrm{V} / \mathrm{W} / \mathrm{m}^{2}\right)$

To measure temperature differences across the specimen, three temperature data loggers are placed from each side of the specimen. HOBO data logger type H08007-02 and BoxCar 3.7 Software were used to measure temperature (Fig. 4b). The data logger has two internal temperature sensors and two external sensors. Further, the data logger is programmable in term of time increment and the start and end time.

\subsection{Calibration of the Measurement Device}

The device was calibrated by testing materials with known thermal conductivity. Four different construction materials were tested for thermal conductivity.

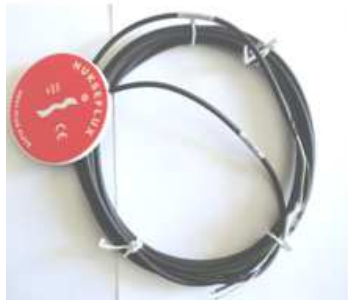

(a)

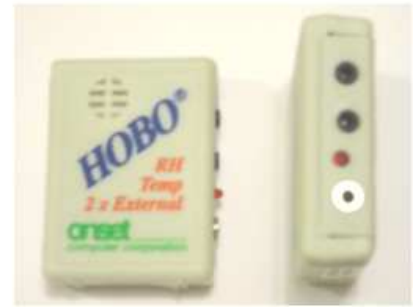

(b)
Fig. 4. (a) HFP01 heat flux sensor, (b) HOBO data logger

The dimensions of the samples were $30.48 \mathrm{~cm} \times 30.48$ $\mathrm{cm} \times 2.54 \mathrm{~cm}(12$ in. $\times 12$ in. $\times 1$ in. $)$. The samples include: Gypsum board (drywall) with $1.27 \mathrm{~cm}(1 / 2$ in.) thick; Oriented Strand Board (OSB) with $1.27 \mathrm{~cm}(1 / 2$ in.) thick; Plywood with $1.27 \mathrm{~cm}(1 / 2$ in.) thick; Mortar with $2.54 \mathrm{~cm}$ (1 in.) thick.

\subsection{Test Setup}

A schematic of thermal conductivity test setup is shown in Fig. 5.

The following testing steps were followed for each test: (a) Specimen was mounted and sealed from all sides; (b) The heat flux sensor was attached to the surface of the specimen with the red side facing the heat source (Fig. 6) and Heat flux was recorded when it reached steady state; (c) Three temperature loggers were mounted to each side of the specimen using double sided tape. The temperature logger was placed in such way that there was a temperature logger placed across from it on the other side; (d) the door of the box was tightly closed and sealed to ensure no heat loss through the edges of the door; (e) turn on the heat source: To reach steady state heat flow, the test was run for an hour and a half; (f) at the end of the test, the data were collected and the thermal conductivity was calculated using Fourier's law (Equation 2).

$\mathrm{Q}=-\mathrm{k} \frac{\Delta \mathrm{T}}{\mathrm{x}}$

Where:

$\mathrm{Q}=$ Heat flux $\mathrm{W} / \mathrm{m}^{2}\left(\mathrm{But} / \mathrm{hr}-\mathrm{ft}^{2}\right)$,

$\Delta \mathrm{T}=$ Temperature difference across material section $\mathrm{K}$ or ${ }^{\circ} \mathrm{C}\left({ }^{\circ} \mathrm{F}\right)$,

$\mathrm{x}=$ Material thickness $\mathrm{m}(\mathrm{ft})$ and

$\mathrm{k}=$ Thermal conductivity $\mathrm{W} / \mathrm{m}$. $\mathrm{k}$ (Btu /h-ft-F).

The device was calibrated by conducting the test on materials with known thermal conductivities. 


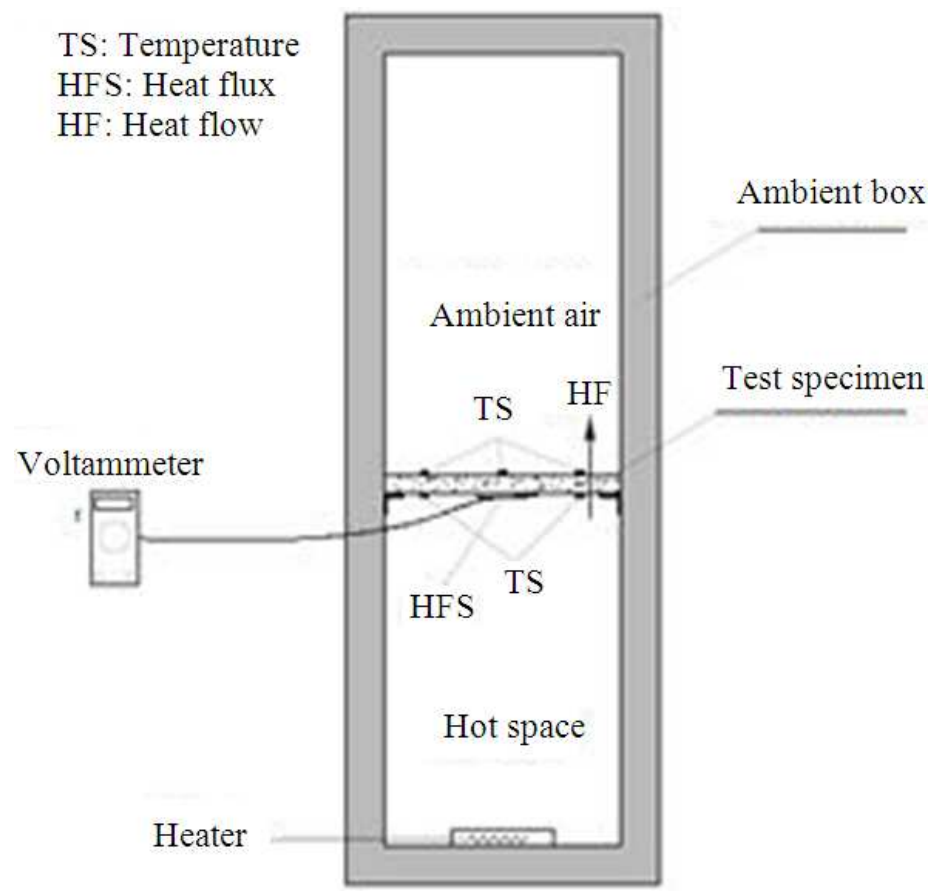

Fig. 5. Schematic of the test set-up

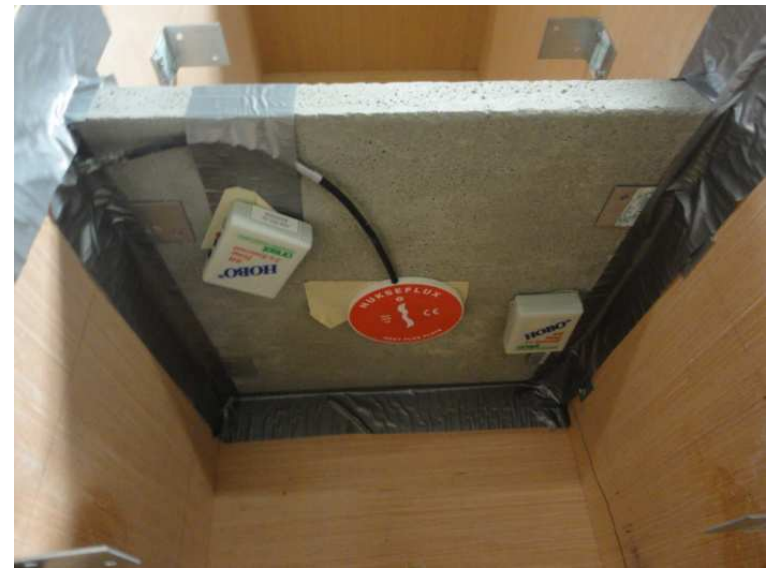

Fig. 6. Heat flux and temperature loggers attached to the specimen

The data of theses reference materials were obtained from online sources (www.engineeringtoolbox.com and www.bca.gov.sg) and from engineering handbooks. The thermal conductivity of the reference materials along with the results are listed in Table 4. A statistical analysis was carried out to determine a correction factor. The statistical analysis yielded an $\mathrm{R}^{2}$ value of 0.995 which indicated a strong relation between the reference and experimental values. Using the statistical analysis, an equation was derived (Equation 3) to modify the experimental values, the equation may be expressed as:

$\mathrm{k}_{\mathrm{m}}=0.964 \mathrm{k}_{\text {exp }}+0.011$

Where:

$\mathrm{k}_{\mathrm{m}}=$ Modified thermal conductivity value and $\mathrm{k}_{\mathrm{exp}}=$ Experimental thermal conductivity value

\section{EXPERIMNETAL RESULTS}

Generally, all mixtures of rubberized cement mortar exhibited a lower unit weight compared to the plain cement mortar which indicates that lightweight construction materials can be obtained by incorporating waste tire materials (crumb rubber) into mix ingredients. Further, an improvement of the specimen's thermal property was achieved and that can be seen by the reduction in the thermal conductivity of mixtures containing crumb rubber.

\subsection{Density and Absorption of Rubber-Mortar}

Results of density and water absorption of rubberized mortar are reported in Table 5 .

The density of the rubberized mortar varied based on the rubber amount and rubber size (Fig. 7). 
The density decreased when the rubber amount increased. Further, it was noticed that rubberized mortar contained powder rubber (\#30) had lower unit weight than the rubberized mortar contained coarser rubber (\#10_20). The unit weight decreased from $1996 \mathrm{Kg} / \mathrm{m} 3$ for plain mortar to 1408,1209 and 1384 which is about $29 \%, 31 \%$ and $35 \%$ with respect to plain mortar when $40 \%$ of the sand was replaced by crumb rubber size \#10_20, mix of \#10_20\&\#30 and $\# 30$, respectively. The density decreased by about $10 \%$ when the percentage of rubber inclusion increased from 10 to 20 and 30 to $40 \%$, however, the decrease was only $7 \%$ when the amount of rubber increased from 20 to $30 \%$. This trend was observed in all mixtures.

The water absorption of all mixtures that contained up $20 \%$ crumb rubber had water absorption lower than that of plain mortar. For the mixtures that contained \#10_20 and mix rubber sizes had water absorption lower than plain mortar. However, mixtures that contained $30 \%$ or more of $\# 30$ crumb rubber had water absorption higher than the plain mortar. Considering the size of rubber particle, the water absorption values of rubberized mortar that contained \#30 crumb rubber were higher than that of \#10_20 and the mix crumb rubber sizes (Fig. 7).

\subsection{Thermal Conductivity of Rubberized Mortar}

Results of the thermal conductivity, k-value, of Rubberized Mortar are tabulated in Table 6 and shown in Fig. 8. Findings show that the thermal conductivity values (k-values) decrease when the amount of rubber increase regardless of the size of crumb rubber. It was found that the $\mathrm{k}$-values of rubberized mortar varied between $0.593 \mathrm{~W} / \mathrm{mK}$ to $0.492 \mathrm{~W} / \mathrm{mK}$ compared to $0.682 \mathrm{~W} / \mathrm{mK}$ for the plain mortar. This is about 13 to $28 \%$ reduction in the thermal conductivity of plain mortar.

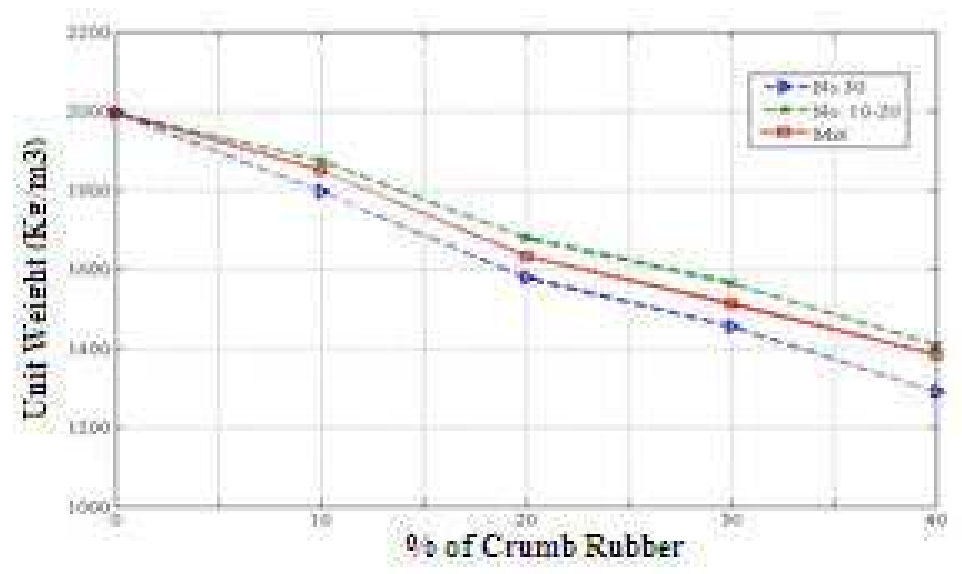

Fig. 7. Density of rubberized mortar

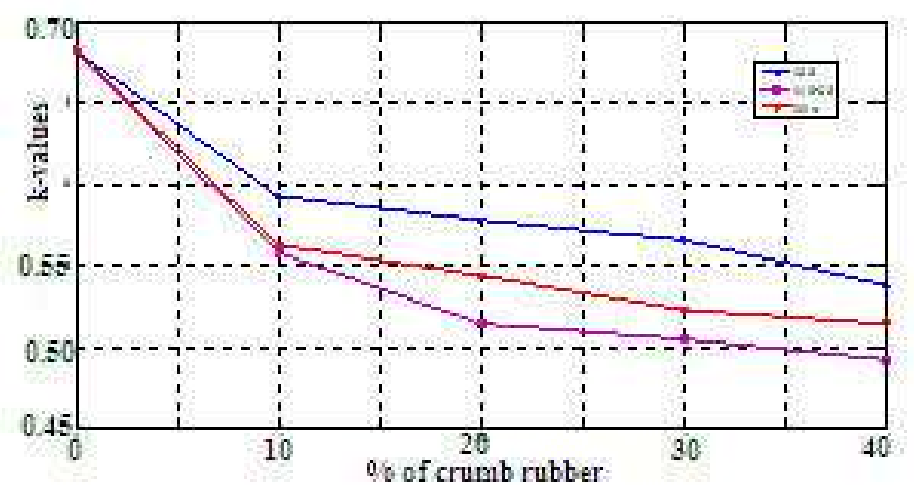

Fig. 8. k Vs. amount and size of crumb rubber 
For different levels of rubber replacement, the decrease in thermal conductivity varied based on the size of rubber particles. From 10 to $20 \%$ rubber addition, thermal conductivity decreased by $2.5-8 \%$. This range reduced to about $2-4 \%$ when the amount increased from 20 to $30 \%$.

Table 4. Experimental versus reference values

\begin{tabular}{lll}
\hline & Conductivity $(\mathrm{W} / \mathrm{m} \mathrm{K})$ \\
& $\begin{array}{l}\text { Reference } \\
\text { values }\end{array}$ & $\begin{array}{l}\text { Test } \\
\text { values }\end{array}$ \\
\hline Sample designation & 0.170 & 0.1760 \\
Gypsum board, $1 / 2$ in thick & 0.170 & 0.1720 \\
Gypsum board, $1 / 2$ in. thick & 0.170 & 0.1790 \\
Gypsum board, $1 / 2$ in. thick & 0.130 & 0.1495 \\
Oriented strand board, $1 / 2$ in. & 0.138 & 0.1304 \\
Plywood with $1 / 2$ in. thick & 0.710 & 0.6820 \\
Mortar, $2.54 \mathrm{~cm}(1$ in.) thick & 0.710 & 0.6720 \\
Mortar, $2.54 \mathrm{~cm}(1$ in.) thick & 0.710 & 0.7340 \\
Mortar, $2.54 \mathrm{~cm}(1$ in.) thick & &
\end{tabular}

Table 5. Density and absorption of rubberized mortar

\begin{tabular}{llll}
\hline Mix ID & $\begin{array}{l}\text { Wet density } \\
\left(\mathrm{kg} / \mathrm{m}^{3}\right)\end{array}$ & $\begin{array}{l}\text { Dry density } \\
\left(\mathrm{kg} / \mathrm{m}^{3}\right)\end{array}$ & $\begin{array}{l}\text { Absorption } \\
(\%)\end{array}$ \\
\hline PM & 1996 & 1815 & 10.00 \\
10M\#10-20 & 1874 & 1756 & 6.75 \\
20M\#10-20 & 1679 & 1562 & 7.50 \\
30M\#10-20 & 1565 & 1430 & 9.40 \\
40M\#10-20 & 1408 & 1269 & 11.00 \\
10M\#30 & 1796 & 1669 & 7.60 \\
20M\#30 & 1578 & 1440 & 9.60 \\
30M\#30 & 1455 & 1305 & 11.50 \\
40M\#30 & 1290 & 1106 & 16.70 \\
10MMix & 1849 & 1716 & 7.70 \\
20MMix & 1633 & 1497 & 9.10 \\
30MMix & 1512 & 1381 & 9.50 \\
40MMix & 1384 & 1238 & 11.80 \\
\hline
\end{tabular}

Table 6. Thermal conductivity of rubberized mortar

\begin{tabular}{lll}
\hline Mixture ID & k-value $(\mathrm{W} / \mathrm{mK})$ & Reduction (\%) \\
\hline PM & 0.682 & 00.0 \\
10M\#30 & 0.593 & 13.1 \\
20M\#30 & 0.578 & 15.2 \\
30M\#30 & 0.566 & 17.0 \\
40M\#30 & 0.538 & 21.2 \\
10MMix & 0.563 & 17.5 \\
20MMix & 0.544 & 20.2 \\
30MMix & 0.523 & 23.3 \\
40MMix & 0.514 & 24.6 \\
10M\#10-20 & 0.558 & 18.2 \\
20M\#10-20 & 0.514 & 24.6 \\
30M\#10-20 & 0.505 & 26.0 \\
40M\#10-20 & 0.492 & 27.8 \\
\hline
\end{tabular}

When rubber content increased from $30 \%$ to $40 \%$, the reduction in the thermal conductivity was about $2-5 \%$. The results also indicated that the size of the crumb rubber had an effect on the thermal conductivity of the mixtures. For instance, at $10 \%$ percentage of $\# 30$, mix and \# 10_20 rubber, the thermal conductivity decreased by $13.1,17.5$ and $18.2 \%$ respectively. The coarser size (\#10_20) had higher effect on the thermal conductivity than the mix and \#30 sizes. This can be attributed to the fact that large particles have greater surface than smaller particles and because the nature of rubber surface that tend to entrap air, large rubber particles entrap more air than smaller sizes. Among the rubber sizes used in this experiment, crumb rubber \#30 seems to have more effect on the thermal conductivity of mortar if rubber amount exceeded $40 \%$.

\section{EMPIRICAL RELATIONSHIP}

An empirical equation of thermal conductivity of rubberized cement mortar was derived based on dry densities of the mixtures tested in this study. Values obtained from the empirical equation (Equation 4) are plotted against the experimental values as shown in Fig. 9 and tabulated in Table 7. The error ranged from $2 \%$ to $9 \%$ which is believed to be acceptable for initial prediction of thermal conductivity of mortar contains crumb rubber:

$$
\mathrm{k}=0.411 \mathrm{e}^{0.0002 \rho}
$$

Table 7. Experimental versus theoretical k-values

\begin{tabular}{|c|c|c|c|}
\hline \multirow[b]{2}{*}{ Mix ID } & \multicolumn{3}{|c|}{ Thermal conductivity } \\
\hline & Experimental & Theoretical & Error $(\%)$ \\
\hline $10 \mathrm{M} \# 10-20$ & 0.558 & 0.584 & 5 \\
\hline 20M\#10-20 & 0.514 & 0.562 & 9 \\
\hline $30 \mathrm{M} \# 10-20$ & 0.505 & 0.547 & 8 \\
\hline 40M\#10-20 & 0.492 & 0.530 & 8 \\
\hline 10MMix & 0.563 & 0.579 & 3 \\
\hline 20MMix & 0.544 & 0.554 & 2 \\
\hline 30MMix & 0.523 & 0.542 & 4 \\
\hline 40MMix & 0.514 & 0.526 & 2 \\
\hline $10 \mathrm{M} \# 30$ & 0.593 & 0.574 & -3 \\
\hline $20 \mathrm{M} \# 30$ & 0.578 & 0.548 & -5 \\
\hline 30M\#30 & 0.566 & 0.534 & -6 \\
\hline 40M\#30 & 0.538 & 0.513 & -5 \\
\hline
\end{tabular}




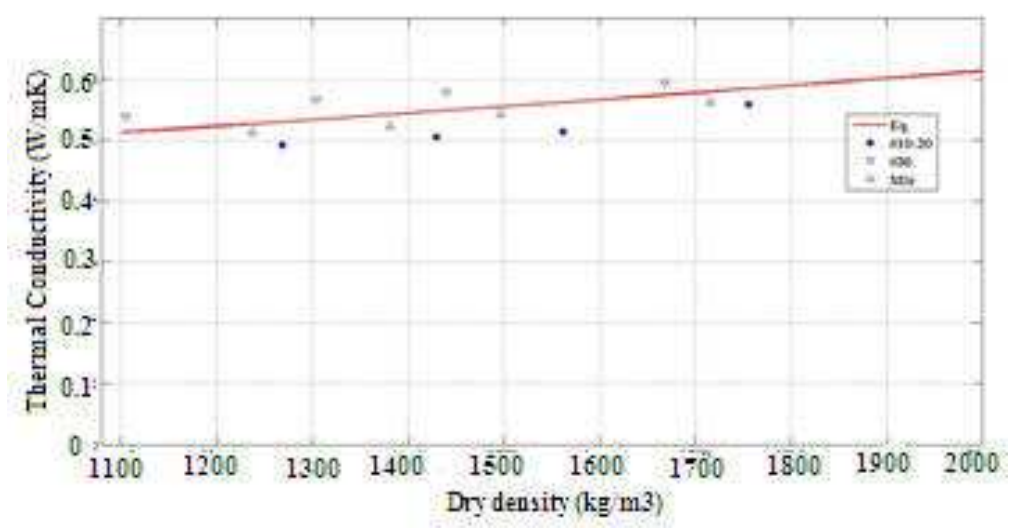

Fig. 9. Experimental Vs. empirical results

\section{DISCUSSION}

\subsection{Density and Absorption of Rubber-Mortar}

All mixtures of rubberized cement mortar exhibited a lower unit weight compared to the plain cement mortar. The main reason behind the reduction in the density as explained by Ling (2011) is attributed to the increase in air content because of the nature of rubber surface which tend to entrap air. The increase in rubber quantity leads to increase in air content which causes the density to decrease. In this study, the density of mixtures contained mixed crumb rubber fell in the territory between the density of mixtures contained \#30 and \#10_20. Sukontasukkul (2009) had a similar observation. The reduction in the unit weight is attributed to rubber lower specific gravity than that of fine aggregate. The variation in the unit weight of mixtures contained different crumb rubber sizes can be also related to the specific gravity since it was the only variable.

Material's ability to resist water absorption is desired property especially in areas expose to aggressive environment. The results obtained in this research showed an improvement of water absorption resistance with respect to the plain mortar. The decrease in water absorption is attributed to the decrease in the porosity of the mixtures and that because of filling the voids by rubber particles. In addition, the nature of rubber which resists water plays an important role in this reduction (Benazzouk et al., 2007; Ganjian et al., 2009). However, beyond $20 \%$ rubber inclusion the water absorption increased due to the reason that the high increase in air content cannot be occupied by rubber particles.

\subsection{Thermal Conductivity of Rubberized Mortar}

Thermal conductivity ( $k$-value) measurement was determined by using a specially designed device. The $k$ value was obtained by taking the averages of heat flux passing through the specimen at steady state condition and temperature difference across the specimen concurrently. These values were used in the Fourier's law (Equation 2) to calculate the k-values. The results were then modified using Equation 3 which was established by comparing the k-value of known materials by $k$-values obtained for the same materials using the designed apparatus.

Experimental results obtained herein show that thermal conductivity of the rubberized mortar deceased when the amount of rubber increased regardless the size of crumb rubber. The decrease in thermal conductivity of mortar contained rubber can be related to two factors, the increase in air content and low thermal conductivity of rubber compared to the paste. Previous studies indicated that the rubber present in cementitious mixtures increases the air content even without adding air-entraining admixture. Benazzouk et al. (2007) reported that air content increase from 2 to $17 \%$ when amount of rubber increased from 0 to $50 \%$. Air has thermal conductivity of $0.0026 \mathrm{~W} / \mathrm{mK}$ which serve to improve the mixture's thermal insulation property. The other factor is the thermal conductivity of rubber particles itself. Rubber thermal conductivity varied between $0.05-0.13 \mathrm{~W} / \mathrm{mK}$ for rubber particle size range between 1-12 mm (Benazzouk et al. 2007). When crumb rubber particles replace sand, which has higher thermal conductivity, the overall thermal conductivity of mixtures decrease. 
It should be mentioned that during the preparation of the specimens, it was observed that the amount of air bubbles was more in the mixtures of larger rubber particles. Also, the workability of rubberized mortar that contained coarse crumb rubber size was better than the one with fine crumb rubber. Rubber particles showed more tendencies to float to the top surface of the specimen at $30 \%$ and more of rubber replacement.

\section{CONCLUSION}

This research investigated the effect of crumb rubber on the thermal conductivity of the rubberized cement mortar. The thermal conductivity was measured using a specially made device based on the principle of common measurement techniques. From the findings of the experimental work, the following conclusions may be drawn:

- The unit weight of rubberized mortar reduced by 35 when $40 \%$ of fine aggregate were replaced with crumb rubber. Also, the unit weight of mixtures contained finer rubber particles was lower than that mixtures contained coarser rubber particles

- Water absorption of mixtures contained up $20 \%$ crumb rubber was lower than that of conventional mixtures. This is an indication that such material can be useful as exterior plaster in regions that exposed to aggressive environmental conditions

- The size of rubber particles had an effect on the thermal conductivity of rubberized mortar. Mixtures contained large size rubber particles had a lower thermal conductivity than the one with smaller size of rubber particles for each level of replacement

- Thermal conductivity of rubberized mortar contained $40 \%$ of rubber inclusion had a thermal conductivity of $0.492 \mathrm{~W} / \mathrm{m}$. K which is about $28 \%$ reduction of the thermal conductivity of conventional mortar. This improvement in the thermal insulation of rubberized mortar can find a practical application as an exterior coating material that can contribute to envelop system of buildings

- Suggested future work include: (a) study the effect of rubberized mortar on the overall energy consumption of buildings and (b) investigate the effect of air voids size and air voids ratio on the thermal conductivity of rubberized mortar materials

\section{REFERENCES}

Benazzouk, A., O. Douzane and M. Que'neudec, 2004. Transport of fluids in cement-rubber composites. Cement Concrete Comp., 26: 21-19. DOI: 10.1016/S0958-9465(02)00119-1

Benazzouk, A.D., T. Langlet, K. Mezreb J.M. Roucoult and M. Quéneudec, 2007. Physicomechanical properties and water absorption of cement composite containing shredded rubber wastes. Cement Concrete Composi., 29: 732-740. DOI: 10.1016/j.cemconcomp.2007.07.001

Bolden, J., T. Abu-Lebdeh and E. Fini, 2013. Utilization of recycled and waste materials in various construction applications. Am. J. Environ. Sci., 9: 14-24. DOI: 10.3844/ajessp.2013.14.24

Duman, V., A. Mladenovic and J. Suput, 2002. Lightweight aggregate based on waste glass and its alkali-silica reactivity. Cement Concrete Res., 32: 223-626. DOI: $10.1016 / \mathrm{S} 0008-$ 8846(01)00663-9

Fini, E., D. Oldham and T. Abu-Lebdeh, 2013. Synthesis and Characterization of Bio-Modified Rubber (BMR) asphalt: A sustainable waste management solution for scrap tire and swine manure. J. Environ. Eng., 139: 1454-1461. DOI: 10.1061/(ASCE)EE.1943-7870.0000765

Fiore, S., M.C. Zanetti and B. Ruffino, 2008. Waste characterization in steel casting and recycling opportunities in Europe. Am. J. Applied Sci., 5: 512-518. DOI: 10.3844/ajassp.2008.512.518

Ganjian, E., M. Khorami and A. Maghsoudi, 2009. Scrap-tire-rubber replacement for aggregate and filler in concrete. Construction Building Materials, 23: 1828-1836. DOI: 10.1016/j.conbuildmat.2008.09.020

James, M.N., W. Choi and T. Abu-Lebdeh, 2011. Use of recycled aggregate and fly ash in concrete pavement. Am. J. Eng. Applied Sci., 4: 201-208. DOI: 10.3844/ajeassp.2011.201.208

Kearsley, E.P. and P.J. Wainwright, 2001. The effect of high fly ash content on the compressive strength of foamed concrete. Cem. Conc. Res, 31: 105-112. DOI: 10.1016/S0008-8846(00)00430-0

Laukaitis, A., R. Zurauskas and J. Keriene, 2005. The effect of foam polystyrene granules on cement composite properties. Cement Conc. Comp., 27: 41-47. DOI: 10.1016/j.cemconcomp.2003.09.004 
Ling, T., 2011. Prediction of density and compressive strength for rubberized concrete blocks. Construction Building Materials, 25: 4303-4306. DOI: 10.1016/j.conbuildmat.2011.04.074

Roshan, A.M.G., M.B. Hosseinian, H. Khalilpasha and R. Amirpour, 2010. Optimization of micro silica in light weight lika concrete. Am. J. Eng. Applied Sci., 3: 449-453. DOI: 10.3844/ajeassp.2010.449.453

Segre, N. and I. Joekes, 2000. Use of tire rubber particles as addition to cement paste. Cement Conc. Res., 30: 1421-1425. DOI: 10.1016/S00088846(00)00373-2
Sukontasukkul, P. and S. Wiwatpattanapong, 2009. Moderate lightweight concrete mixed with recycled crumb rubber. Thammasat Int. J. Sci. Tech., 14: 1-9.

Sukontasukkul, P., 2009. Use of crumb rubber to improve thermal and sound properties of pre-cast concrete panel. Construction Building Materials, 23: 1084-1092.

DOI: 10.1016/j.conbuildmat.2008.05.021

Yue, Y.L., Li G.Z., Xu X.S. and Z.J. Zhao, 2000. Properties and microstructures of plan-fiberreinforced cement-based composites. Cement Concrete Res, 30: 1983-1986. DOI: 10.1016/S00088846(00)00376-8 